\title{
CONSENSULIDADE NA ADMINISTRAÇÃO PÚBLICA: UMA ANÁLISE DO ACORDO DE LENIÊNCIA PREVISTO NA LEI ANTICORRUPÇÃO
}

\author{
Viviane Duarte Couto de Cristo ${ }^{1}$ \\ Luísa Munhoz Bürgel Ramidoff ${ }^{2}$
}

\begin{abstract}
Resumo: Diante dos apelos sociais das recentes manifestações no Brasil, a Lei Anticorrupção é promulgada com o fim de alcançar a pessoa jurídica por atos de corrupção. $\mathrm{O}$ acordo de leniência, previsto nesta nova norma, surge como uma ferramenta consensual entre a Administração Pública e o infrator na obtenção de provas em troca de benefícios, sistema que já funciona há décadas em outros países, em especial nos Estados Unidos. Todavia, tal instituto é motivo de duras críticas por parte da doutrina, o que pode indicar óbice à sua consolidação no mundo jurídico.
\end{abstract}

Palavras-chave: Acordo de Leniência; consensualidade; Lei $n^{\circ}$ 12.846/2013; Lei Anticorrupção; combate à corrupção.

\section{CONSENSUALITY IN THE PUBLIC ADMINISTRATION: AN ANALYSIS OF THE LENIENCY AGREEMENT PREDICTED IN THE ANTI-CORRUPTION LAW}

\begin{abstract}
Ahead of the social appeals of Brazil's recent manifestations, the anti-corruption law it's promulgated in order to reach the legal company by corruption acts. The leniency agreement, predicted in the newest rule, emerges as a consensual instrument among the public administration and the lawbreaker, with the proof acquisition in exchange of benefits, system that has been working in other countries, especially the United States, for decades. However, such institute is source of criticism by the doctrine, which could be an obstacle to its consolidation in the juridical world.
\end{abstract}

Key-words: Leniency agreement; consensuality; Law N. 12.846/2013; Anti-corruption Law; corruption combat.

\footnotetext{
${ }^{1}$ Mestranda em Direito Empresarial e Cidadania pelo Centro Universitário Curitiba - UniCuritiba. Especialista em Administração Pública pela UNIBRASIL. Graduada em Direito pela Faculdade de Direito de Curitiba. ExDocente da Facsul, ESA (OAB-PR) e IMAP (Prefeitura de Curitiba). Ex-Procuradora Geral do Município de Campina Grande do Sul. Membro do Grupo de Pesquisa: Intervenção do Estado e da Administração Pública no domínio econômico e social: políticas públicas com vistas à promoção do desenvolvimento nacional sustentável (da sanção punitiva à sanção premial. Membro da Comissão de Gestão Pública, Transparência e Controle da OAB-PR. Advogada. viviane@duartecristo.com.br. http://lattes.cnpq.br/9328608690102866

${ }^{2}$ Mestranda em Direito Empresarial e Cidadania pelo Centro Universitário Curitiba - UniCuritiba (2016/2018). Pós-Graduanda em Direito Penal e Processo Penal pelo Centro Universitário Curitiba - UniCuritiba (2015/2017). Pós-Graduanda em Direito Penal e Criminologia pelo Centro Universitário Internacional - UNINTER (2016/2018). Graduada em Direito pelo Centro Universitário Curitiba - UniCuritiba (2015). Tem experiência na área de Direito, com ênfase em Direito Penal e Processo Penal. luh_ramidoff@hotmail.com. http://lattes.cnpq.br/2689969569100642
} 


\section{INTRODUÇÃO}

Com a modernização do direito administrativo brasileiro, questões como a aplicação obrigatória da sanção pelo Poder Público passaram a ser relativizadas com a inclusão de instrumentos legais de consensualidade, como é o caso do acordo de leniência previsto na Lei $n^{\circ} 12.846 / 13$ (Lei Anticorrupção).

A atualidade do tema já demonstra a relevância para ser tratado no meio acadêmico, o que é reforçado pela necessária ampliação do controle da corrupção que gera efeitos tão nocivos à sociedade.

A Lei Anticorrupção, incentivada pelas manifestações populares recentes, compõe um sistema legal de defesa moral, ao lado de outros dispositivos como a Lei de Improbidade Administrativa (Lei $\mathrm{n}^{\circ}$ 8429/92), Lei e Licitações e Contratos Administrativos (Lei $\mathrm{n}^{\circ}$ 8.666/93), Lei da Ficha Limpa (LC 135/2010), Lei da Defesa da Concorrência (Lei n ${ }^{\circ}$ 12.529/11), além dos crimes desta natureza previstos no Código Penal. Inova com a penalização civil e administrativa de pessoas jurídicas (MOREIRA NETO e FREITAS, 2014, p. 10).

Referida Lei prevê mecanismos de colaboração com o Poder Público, na identificação do esquema criminoso, obtenção de provas e rapidez na recuperação de valores desviados através de acordo de leniência, além de incentivar a implantação de programas de integridade (compliance), com vistas ao estabelecimento de uma cultura de prevenção e ética empresarial.

A metodologia utilizada é a pesquisa bibliográfica, que muito embora seja escassa diante da novidade do tema, é tratada com certa profundidade pelos autores que se dedicaram ao seu estudo. Todavia a análise legal demanda certo cuidado, uma vez que muitas obras e artigos foram produzidos sob a égide da Medida Provisória $n^{\circ} 703 / 2015$, que perdeu vigência em 29/05/2016, a qual ensejou inúmeras modificações, e por isso carecem ser atualizadas.

Visando atingir os objetivos do estudo, far-se-á um recorte metodológico para a investigação dos aspectos relacionados às empresas, sem avaliar os efeitos do acordo para o Estado.

Este estudo se propõe a analisar em que medida o acordo de leniência, previsto na Lei anticorrupção, pode ser mostrar atrativo às pessoas jurídicas, contribuindo como instrumento consensual de controle da corrupção no país. 


\section{Analisando a possibilidade de consensualidade na Administração pública}

O poder-dever sancionador do direito administrativo brasileiro passou por grande modificação nos últimos quinze anos, ampliando os horizontes da consensualização. Trata-se de reflexo das experiências estrangeiras, assim como segue o avanço da sociedade da informação. A atuação estatal que era verticalizada passou a dialogar com a sociedade e particulares, possibilitando a negociação com infratores como ocorre nos acordos de leniência. Este avanço, todavia, não foi contemplado amplamente na disciplina de Processo Administrativo, caminhando a passos lentos em legislações pontuais (MARRARA, 2015, p. $525)$.

A consensualidade possibilita ao infrator que firme um acordo com a finalidade de reduzir ou substituir sanção administrativa que estaria sujeito por determinada infração à ordem legal.

Mas para que seja possível a consensualização na esfera pública, afastando ou mitigando a sanção administrativa, há que existir previsão legal expressa.

Para Daniel Ferreira:

Bem ou mal, a ordem jurídica se modificou e, hoje, nem sempre estipula a sanção administrativa como a adequada e necessária resposta jurídica ao ilícito administrativo, a ponto mesmo de eventualmente autorizar o trancamento de sua apuração em troca de algumas obrigações, além da prévia recomposição do dano, quando existente. Tudo porque, repita-se, a finalidade da sanção não é a de punir, mas apenas a de desestimular condutas administrativamente reprováveis.

Importante destacar essa premissa de que a finalidade da sanção é a desestimulação de condutas reprováveis, que demonstra alcançar o interesse público quando são aplicadas alternativas à sanção.

Também pode-se considerar que uma forma de alternativa à sanção possibilite, com mais eficiência, a recomposição do dano, que muitas vezes se mostra incerto, moroso e custoso. Ainda cabe lembrar que a Administração Pública deve ser eficiente, conforme dispõe o art. $37 \mathrm{CRF}$ que integra a eficiência como princípio norteador. 
Uma das alternativas para a resolução de conflitos administrativos é o Termo de Compromisso (TAC), que está albergado pela Lei n ${ }^{\circ} 7.347 / 85^{3}$ (Lei da Ação Civil Pública), em seu art. $5^{\circ}, \S 6^{\circ}$. O TAC é largamente aplicado em questões que envolvem o direito ambiental, nos termos da Lei $\mathrm{n}^{\mathrm{o}}$ 9.605/98, que dispõe sobre as sanções penais e administrativas derivadas de condutas e atividades lesivas ao meio ambiente, tanto às pessoas físicas como jurídicas.

O Termo de Ajustamento de Conduta também tem sido utilizado pelas Agências Reguladoras, pela CVM (Comissão de Valores Mobiliários) e pelo CADE (Conselho Administrativo de Defesa Econômica).

O acordo de leniência, que será adiante melhor abordado, também se qualifica como uma alternativa para mitigar integral ou parcialmente a sanção administrativa, em relação consensual com o Poder Público.

\title{
3. Breves notas sobre a questão da corrupção no Brasil e a Lei Anticorrupção
}

A corrupção no Brasil parece ter raízes profundas, e se compõe de agentes corruptos e corruptores. Jessé Souza (2009, p. 105) chama a atenção para esta questão:

\begin{abstract}
Como no "culturalismo", dominante até hoje entre nós, a "cultura" nunca muda, a modernização brasileira a rigor nunca aconteceu. É por conta disso que o discurso da "corrupção generalizada", ou melhor, da corrupção localizada no Estado, que permite "divinizar" o mercado como espaço da virtude por excelência, pode, ainda hoje em dia, ser percebido como um traço cultural português do Portugal de 1500. O mesmo acontece com a tal cultura do "favor" e do "privilégio" como nosso traço "cultural" principal.
\end{abstract}

Aliado a outros problemas graves, muitos deles atribuídos ao sistema capitalista, a corrupção amplia as mazelas sociais. Eduardo Galeano (1976, p. 07) traz fortes e verdadeiras reflexões sobre a pobreza na América Latina:

São secretas as matanças da miséria na América Latina; em cada ano explodem, silenciosamente, sem qualquer estrépito, três bombas de Hiroxima sobre estes povos, que têm o costume de sofrer com os dentes cerrados. Esta violência sistemática e real continua aumentando: seus crimes não se difundem na imprensa marrom, mas sim nas estatísticas da FAO. Ball diz que a impunidade é ainda possível, porque os pobres não podem desencadear uma guerra mundial [...].

\footnotetext{
${ }^{3}$ Lei oํ $7.347 / 85$. Art. $5^{\circ}$. $\S 6^{\circ}$ Os órgãos públicos legitimados poderão tomar dos interessados compromisso de ajustamento de sua conduta às exigências legais, mediante cominações, que terá eficácia de título executivo extrajudicial. (Incluído pela Lei № 8.078, de 11.9.1990).
} 
O combate à corrupção tem que ser buscado como um compromisso de toda sociedade, com a mudança em cada empresa, em cada cidadão, tanto na sua conduta ética do dia-a-dia, como na participação e controle dos atos governamentais. Neste sentido, de acordo com (PADILHA FILHO, 2010, p. 35):

Perpetuou-se, nos padrões de conduta individual, a crença equivocada de que os bens e valores que integram a Administração Pública pertencem a um 'corpo estranho e distinto', que é o ente estatal. [...] Não houve nesta marcha evolutiva do Estado brasileiro, mas que agora sofre ruptura pragmática (com a crescente e desejável participação da sociedade civil na fiscalização dos atos públicos), a preocupação no desenvolvimento de uma consciência coletiva, um substrato ético mínimo, a nortear tanto as condutas dos agentes públicos, quanto daqueles que integram o setor privado, no sentido de incutir em suas mentes, e em seu proceder diário, uma verdade reveladora, de que a titularidade dos valores e bens públicos é de todos, deixando ínsito, a esta mesma coletividade co-responsável, a urgência de sua proteção.

Muito embora não faltasse legislação sancionatória contra atos de corrupção (lei de improbidade administrativa, lei de licitações, leis penais), as pessoas jurídicas não eram atingidas tão profundamente como na recente Lei Anticorrupção (Lei no 12.846/13), que sofreu forte influência dos acordos internacionais e da legislação estrangeira. Percebe-se a mudança de um paradigma ao buscar também punir mais severamente o corruptor.

O Brasil é signatário de vários acordos envolvendo compromissos neste sentido. Entre eles se destacam a "Convenção Interamericana contra a corrupção" ${ }^{4}$ junto à Organização dos Estado Americanos - OEA (1996); e a "Convenção das Nações Unidas contra a corrupção" ${ }^{5}$ perante a Organização das Nações Unidas - ONU (2003), com ratificações legais posteriores, em 2002 e 2007 respectivamente.

\footnotetext{
${ }^{4}$ Aprovação: Decreto Legislativo no ${ }^{\circ}$ 152/02 e Promulgação: Decreto no 4.410/02. Texto completo da Convenção disponível em <http://www.oas.org/es/sla/ddi/tratados_multilaterales_interamericanos_B58_contra_Corrupcion.asp> Acesso em 24 nov. 2016.

${ }_{5}$ Ratificação: Decreto Legislativo no 348/05 e Promulgação: Decreto Presidencial no 5.687/06. Em relação à responsabilidade de Pessoa Jurídica a Convenção das Nações Unidas contra a corrupção tem o seguinte teor: "Artigo 26. Responsabilidade das pessoas jurídicas. 1. Cada Estado Parte adotará as medidas que sejam necessárias, em consonância com seus princípios jurídicos, a fim de estabelecer a responsabilidade de pessoas jurídicas por sua participação nos delitos qualificados de acordo com a presente Convenção. 2. Sujeito aos princípios jurídicos do Estado Parte, a responsabilidade das pessoas jurídicas poderá ser de índole penal, civil ou administrativa. 3. Tal responsabilidade existirá sem prejuízo à responsabilidade penal que incumba às pessoas físicas que tenham cometido os delitos. 4. Cada Estado Parte velará em particular para que se imponham sanções penais ou não penais eficazes, proporcionadas e dissuasivas, incluídas sanções monetárias, às pessoas jurídicas consideradas responsáveis de acordo com o presente Artigo." Texto completo da Convenção disponível em <https://www.unodc.org/documents//po-brazil//Topics_corruption/Publicacoes/2007_UNCAC_Port.pdf> Acesso em 24 nov. 2016
} 
Mesmo com os acordos internacionais firmados e ratificados, o Projeto de Lei que deu origem à Lei anticorrupção tinha lenta tramitação por mais de três anos. Todavia foi rapidamente colocado em pauta e votado, em razão que pode ser atribuída à forte pressão social diante das inúmeras manifestações cidadãs que ocorreram em todo país em junho de 2013. A aprovação do projeto se deu em 15 dias sem a devida discussão, motivo de imperfeições. (SANTOS, BERTONCINI e CUSTÓDIO FILHO, 2014, p. 07).

A lei anticorrupção brasileira ainda foi fortemente influenciada pelo instituto norte americano FCPA - Foreign Corruption Practice Act (1977) e BA - Bribery Act, da Grã Bretanha (2011).

Para Marçal Justen Filho além de responsabilizar a pessoa jurídica "[...] a lei impõe o dever de diligência especial no âmbito das empresas privadas, determinando-lhes que estruturem as suas atividades de modo a impedir que algum sujeito a elas vinculado pratique conduta de corrupção." (2013, p. 02).

A Lei anticorrupção brasileira moderniza a sanção administrativa no sentido de penalizar agentes do mercado, na tentativa de barrar esta cadeia que permeia o público e o privado. Com isso há um capítulo inteiro nesta legislação sobre a prevenção de atos ilícitos no âmbito empresarial, e a relevância da implantação de mecanismos de Programas de Integridade e controle interno, o que pode ser uma tentativa de modificação real da sociedade a partir da mudança no seio das pessoas jurídicas, que além da finalidade de obter lucro, também possui responsabilidade social em conformidade com ditame constitucional.

\section{O acordo de leniência na Lei anticorrupção}

O acordo de leniência é um "ato convencional" no qual a Administração Pública e o particular negociam a redução de rol de punições a que a pessoa jurídica está sujeita, mediante o cumprimento de certos requisitos (ZOCKUN, 2016, p. 01).

A previsão do acordo de leniência ora em estudo encontra-se inserido na Lei Anticorrupção (Lei n ${ }^{\circ}$ 12.846/13) a partir de seu artigo 16, e conta com a seguinte redação:

Art. 16. A autoridade máxima de cada órgão ou entidade pública poderá celebrar acordo de leniência com as pessoas jurídicas responsáveis pela prática dos atos previstos nesta Lei que colaborem efetivamente com as investigações e o processo administrativo, sendo que dessa colaboração resulte:

I - a identificação dos demais envolvidos na infração, quando couber; e

II - a obtenção célere de informações e documentos que comprovem o ilícito sob apuração. 
$\S 1^{\text {o }} \mathrm{O}$ acordo de que trata o caput somente poderá ser celebrado se preenchidos, cumulativamente, os seguintes requisitos:

I - a pessoa jurídica seja a primeira a se manifestar sobre seu interesse em cooperar para a apuração do ato ilícito;

II - a pessoa jurídica cesse completamente seu envolvimento na infração investigada a partir da data de propositura do acordo;

III - a pessoa jurídica admita sua participação no ilícito e coopere plena e permanentemente com as investigações e o processo administrativo, comparecendo, sob suas expensas, sempre que solicitada, a todos os atos processuais, até seu encerramento.

A natureza do acordo de leniência da Lei anticorrupção é a mesma da que já era aplicada ao direito antitruste, com certas particularidades. (SANTOS, BERTONCINI e CUSTÓDIO FILHO. 2014. p. 233).

Trata-se da possibilidade de aproximação do Estado com a empresa infratora, impensável há décadas atrás, no sentido de colaborar no desvelamento de crimes de corrupção de grande complexidade, assim como ocorre com as pessoas físicas na delação premiada (direito penal). Não se trata, porém, de negociar e dispor do interesse público, mas de alcançar o embasamento e a solução de processos acusatórios, o que não seria possível pelo método tradicional. Tratando-se de uma "via utilitarista" eleita pelo legislador. (MARRARA, 2015, p. 511).

Thiago Marrara continua explicitando sobre dúvidas que podem ser levantadas em relação à violação de princípios constitucionais, como da indisponibilidade de interesses públicos primários (isonomia e a legitimidade para o ato) ${ }^{6}$. Para o autor tratam-se de novas premissas, embasadas na consensualidade do poder sancionador, e que não violariam a Constituição Federal. (MARRARA, 2015, p. 512).

O objeto do acordo de leniência é alternatividade das sanções decorrentes dos ilícitos previsto no art. $5^{\circ}$ da Lei Anticorrupção ${ }^{7}$ e na Lei de Licitações (Lei n ${ }^{\circ}$ 8.666/93), mediante

\footnotetext{
${ }^{6}$ Sobre legitimidade e adequação constitucional do acordo de leniência, consultar "O acordo de Leniência: uma análise de sua compatibilidade constitucional e legitimidade." (SALES e BANNWART JÚNIOR, 2015).

${ }^{7}$ Art. $5^{\circ}$ Constituem atos lesivos à administração pública, nacional ou estrangeira, para os fins desta Lei, todos aqueles praticados pelas pessoas jurídicas mencionadas no parágrafo único do art. $1^{\underline{0}}$, que atentem contra o patrimônio público nacional ou estrangeiro, contra princípios da administração pública ou contra os compromissos internacionais assumidos pelo Brasil, assim definidos:

I - prometer, oferecer ou dar, direta ou indiretamente, vantagem indevida a agente público, ou a terceira pessoa a ele relacionada;

II - comprovadamente, financiar, custear, patrocinar ou de qualquer modo subvencionar a prática dos atos ilícitos previstos nesta Lei;

III - comprovadamente, utilizar-se de interposta pessoa física ou jurídica para ocultar ou dissimular seus reais interesses ou a identidade dos beneficiários dos atos praticados;

IV - no tocante a licitações e contratos:
} 
acordo entre empresa e Poder Público que também se beneficia, mediante os requisitos seguintes:

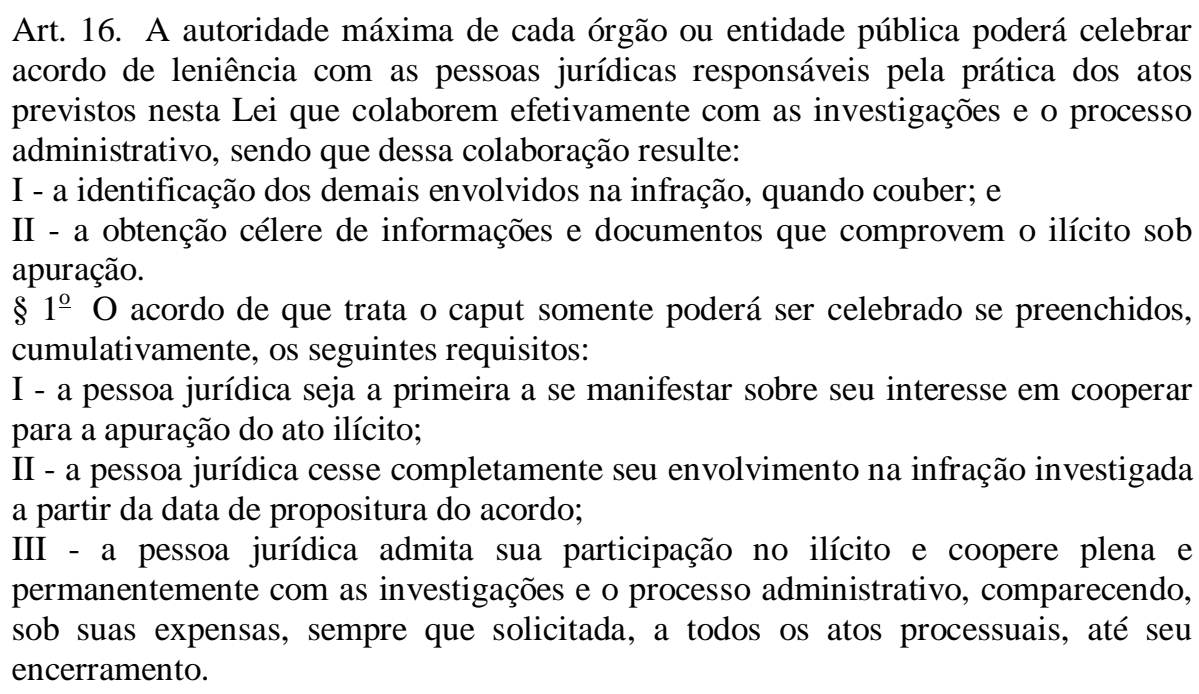

A competência para a instauração e julgamento do Processo Administrativo, assim como para celebrar acordo de leniência, é da autoridade máxima de cada ente público (caput dos art. $8^{\circ}$ e 16). No âmbito federal, competirá à Controladoria Geral da União processar e julgar concorrentemente, competindo-lhe também avocar os processos em andamento para exame e correção (art. $8^{\circ} \S 2^{\circ}$ ).

A pessoa jurídica que firmar o acordo de leniência e cumpri-lo integralmente terá os seguintes benefícios: i) isenção da sanção de publicação extraordinária da decisão condenatória; ii) não proibição em receber incentivos, subsídios, subvenções, doações ou empréstimos de órgãos ou entidades públicas e de instituições financeiras públicas ou

a) frustrar ou fraudar, mediante ajuste, combinação ou qualquer outro expediente, o caráter competitivo de procedimento licitatório público;

b) impedir, perturbar ou fraudar a realização de qualquer ato de procedimento licitatório público;

c) afastar ou procurar afastar licitante, por meio de fraude ou oferecimento de vantagem de qualquer tipo;

d) fraudar licitação pública ou contrato dela decorrente;

e) criar, de modo fraudulento ou irregular, pessoa jurídica para participar de licitação pública ou celebrar contrato administrativo;

f) obter vantagem ou benefício indevido, de modo fraudulento, de modificações ou prorrogações de contratos celebrados com a administração pública, sem autorização em lei, no ato convocatório da licitação pública ou nos respectivos instrumentos contratuais; ou

g) manipular ou fraudar o equilíbrio econômico-financeiro dos contratos celebrados com a administração pública;

V - dificultar atividade de investigação ou fiscalização de órgãos, entidades ou agentes públicos, ou intervir em sua atuação, inclusive no âmbito das agências reguladoras e dos órgãos de fiscalização do sistema financeiro nacional. 
controladas pelo Poder Público; iii) redução da penalidade de multa em até dois terços do valor que seria aplicável (art. 16, § $2^{\circ}$ ); iv) isenção ou atenuação das sanções previstas no art. 86 a art. 88 da Lei ${ }^{\circ} 8.666 / 93^{8}$ (art. 17).

Importante ressaltar que o acordo de leniência não exime o infrator da reparação integral do dano causado (art. 16, $\S 3^{\circ}$ ).

O primeiro benefício, de isenção de publicação extraordinária da condenação parece uma decorrência lógica do próprio acordo firmado, uma vez que inexistirá neste caso decisão condenatória a ser publicada.

Mesmo considerando que a publicação de decisão condenatória teria efeito nocivo à imagem da empresa ${ }^{9}$, mais prejudicial quanto maior for seu espaço no mercado, há que se

\footnotetext{
${ }^{8}$ Art. 86. O atraso injustificado na execução do contrato sujeitará o contratado à multa de mora, na forma prevista no instrumento convocatório ou no contrato.

$\S 1^{\circ}$ A multa a que alude este artigo não impede que a Administração rescinda unilateralmente o contrato e aplique as outras sanções previstas nesta Lei.

$\S 2^{\mathrm{o}}$ A multa, aplicada após regular processo administrativo, será descontada da garantia do respectivo contratado.

$\S 3^{\circ}$ Se a multa for de valor superior ao valor da garantia prestada, além da perda desta, responderá o contratado pela sua diferença, a qual será descontada dos pagamentos eventualmente devidos pela Administração ou ainda, quando for o caso, cobrada judicialmente.
}

Art. 87. Pela inexecução total ou parcial do contrato a Administração poderá, garantida a prévia defesa, aplicar ao contratado as seguintes sanções:

I - advertência;

II - multa, na forma prevista no instrumento convocatório ou no contrato;

III - suspensão temporária de participação em licitação e impedimento de contratar com a Administração, por prazo não superior a 2 (dois) anos;

IV - declaração de inidoneidade para licitar ou contratar com a Administração Pública enquanto perdurarem os motivos determinantes da punição ou até que seja promovida a reabilitação perante a própria autoridade que aplicou a penalidade, que será concedida sempre que o contratado ressarcir a Administração pelos prejuízos resultantes e após decorrido o prazo da sanção aplicada com base no inciso anterior.

$\S 1^{o}$ Se a multa aplicada for superior ao valor da garantia prestada, além da perda desta, responderá o contratado pela sua diferença, que será descontada dos pagamentos eventualmente devidos pela Administração ou cobrada judicialmente.

$\S 2^{-}$As sanções previstas nos incisos I, III e IV deste artigo poderão ser aplicadas juntamente com a do inciso II, facultada a defesa prévia do interessado, no respectivo processo, no prazo de 5 (cinco) dias úteis.

$\S 3^{\circ}$ A sanção estabelecida no inciso IV deste artigo é de competência exclusiva do Ministro de Estado, do Secretário Estadual ou Municipal, conforme o caso, facultada a defesa do interessado no respectivo processo, no prazo de 10 (dez) dias da abertura de vista, podendo a reabilitação ser requerida após 2 (dois) anos de sua aplicação.

Art. 88. As sanções previstas nos incisos III e IV do artigo anterior poderão também ser aplicadas às empresas ou aos profissionais que, em razão dos contratos regidos por esta Lei:

I - tenham sofrido condenação definitiva por praticarem, por meios dolosos, fraude fiscal no recolhimento de quaisquer tributos;

II - tenham praticado atos ilícitos visando a frustrar os objetivos da licitação;

III - demonstrem não possuir idoneidade para contratar com a Administração em virtude de atos ilícitos praticados.

9 A publicação extraordinária da decisão condenatória: "Trata-se de hipótese de tornar pública a condenação sofrida, para submeter a pessoa jurídica condenada pelo cometimento dos atos ilícitos de corrupção ao jugo da sociedade. É sanção bastante significativa e pode produzir consequências mais severas para as pessoas jurídicas 
ponderar que ao firmar acordo de leniência a empresa acaba por se expor de certa forma, uma vez que há divulgação, pelo princípio da publicidade dos atos administrativos, de que foi firmado o acordo envolvendo atos de corrupção. Seria uma amenização em ser vista como infratora colaboradora.

Também cabe melhor análise o benefício que prevê a redução da penalidade, uma vez que não há disposição na lei, ou mesmo na sua regulamentação, sobre a graduação desta diminuição, não há requisitos para tanto, sabendo-se apenas que a redução máxima será de até dois terços, criando uma grande margem discricionária ao Poder Público, e insegurança ao interessado. Tal assunto será abordado em item próprio mais adiante.

\subsection{A alteração legislativa da lei anticorrupção e aspectos da aplicabilidade do acordo de leniência}

A Lei $n^{\circ}$ 12.846/13, publicada em 01/08/2013, entrou em vigor 180 (cento e oitenta) dias após a data de sua publicação, ou seja, em 29/01/2014.

A Medida Provisória no 703 (MP 703/15), que vigorou desde sua publicação (21/12/2015) trouxe várias modificações no acordo de leniência, porém teve sua vigência encerrada em 29/05/2016.

A intenção desta alteração era a de flexibilizar a penalização às empresas, no sentido de favorecer que fossem firmados acordos, para preservação de empregos, em especial para possibilitar que empresas pudessem continuar participando de licitações. ${ }^{10}$

As principais alterações que a MP 703/15 trazia no sentido de ampliar os efeitos de alternatividade da pena eram: i) a possibilidade do acordo de leniência afastar a

do que a pena pecuniária. A boa reputação das empresas tem, contemporaneamente, especialmente no que tange às grandes corporações, valor econômico direto inegável. Um abalo da reputação ética pode produzir danos econômicos inestimáveis. Em uma ambiência corporativa e de mercado que preza pela responsabilidade social que inclui o zelo pela coisa pública e abominação de práticas de corrupção - a divulgação da prática e da condenação por atos ilegais violadores de preceitos éticos fundamentais pode produzir efeitos devastadores à imagem com reflexos importantes nas relações comerciais." (SANTOS, BERTONCINI e CUSTÓDIO, 2014 , p. 163-164)

10 "O relator da MP, deputado Paulo Teixeira (PT-SP), defendeu seu relatório numa das reuniões da Comissão Mista. A experiência internacional, disse o deputado, trabalha o acordo de leniência para preservar empregos, a partir do combate à corrupção e do desenvolvimento econômico das empresas que cometeram ilícitos. — Vários parlamentares vieram me cumprimentar dizendo o seguinte: eu concordo com o seu relatório, o problema é o momento. O momento é conturbado - disse.

Segundo ele, havia uma visão muito punitiva por parte dos integrantes da Comissão Mista sobre o uso da leniência. Teixeira ressaltou que, atualmente, há quase 9 mil empresas inabilitadas para trabalhar com o Estado brasileiro. Para ele, esse número já levaria à necessidade de se revisar as regras." Notícia da Agência Senado. "MP dos acordos de leniência perde a validade". Senado Federal, 31 mai. 2016. Disponível em: <http://www12.senado.leg.br/noticias/materias/2016/05/31/mp-dos-acordos-de-leniencia-perde-a-validade> Acesso em 27/11/2016. 
responsabilidade da pessoa jurídica na esfera judicial; e ii) o impedimento do ajuizamento, ou prosseguimento, de ações relativas à Lei de Improbidade Administrativa (Lei $\mathrm{n}^{\circ}$ 8.429/92) e das sanções judiciais previstas no art. 19 da Lei Anticorrupção contra a pessoa jurídica que firmasse o acordo.

Assim, a pessoa jurídica ao firmar o acordo de leniência, momento em que deveria "admitir sua participação no ilícito" (art. 16, § 1º inciso III da Lei Anticorrupção), teria a garantia de não se sujeitar às penalidades da Lei de Improbidade Administrativa e às penas decorrentes de responsabilização judicial previstas na Lei Anticorrupção, que são extremamente gravosas como a dissolução compulsória da empresa (art. 19, inciso III).

O fim da vigência da MP 703/15 além de excluir as novas disposições, ainda fez voltar a redação original de vários dispositivos, criando uma situação bem peculiar na aplicação do direito e em relação às doutrinas sobre o tema.

Cabe explicitar que a legislação como se encontra, no que se refere à leniência, pode voltar a ser alterada em breve, uma vez que estão em trâmite, na Câmara dos Deputados, pelo menos dois Projetos de Lei neste sentido (Projetos de Lei no 3636/2015 e 5280/2016) ${ }^{11}$.

O Decreto $n^{\circ}$ 8.420/2015 (publicado em 19/03/2015), veio regulamentar a Lei Anticorrupção. Nesta regulamentação foi definido o rito do Processo Administrativo de Responsabilização - PAR, que apura os ilícitos definidos na Lei.

Outro aspecto importante da regulamentação foi de parametrização dos valores das multas (art. 17), com critério detalhado de escalonamento, e no art. 18 aponta os fatores para a redução da penalidade, como a existência e aplicação de programa de integridade na empresa $^{12}$.

\footnotetext{
${ }^{11}$ Notícia da Agência Senado. "MP dos acordos de leniência perde a validade". Senado Federal, 31 mai. 2016. Disponível em: <http://www12.senado.leg.br/noticias/materias/2016/05/31/mp-dos-acordos-de-leniencia-perdea-validade> Acesso em 27/11/2016.

${ }^{12}$ Art. 17. O cálculo da multa se inicia com a soma dos valores correspondentes aos seguintes percentuais do faturamento bruto da pessoa jurídica do último exercício anterior ao da instauração do PAR, excluídos os tributos:

I - um por cento a dois e meio por cento havendo continuidade dos atos lesivos no tempo;

II - um por cento a dois e meio por cento para tolerância ou ciência de pessoas do corpo diretivo ou gerencial da pessoa jurídica;

III - um por cento a quatro por cento no caso de interrupção no fornecimento de serviço público ou na execução de obra contratada;

IV - um por cento para a situação econômica do infrator com base na apresentação de índice de Solvência Geral - SG e de Liquidez Geral - LG superiores a um e de lucro líquido no último exercício anterior ao da ocorrência do ato lesivo;

V - cinco por cento no caso de reincidência, assim definida a ocorrência de nova infração, idêntica ou não à anterior, tipificada como ato lesivo pelo art. $5^{\circ}$ da Lei ${ }^{\circ} 12.846$, de 2013, em menos de cinco anos, contados da publicação do julgamento da infração anterior; e
} 
Em relação ao acordo de leniência, o Decreto repete os requisitos da lei, trazendo algumas inovações:

Art. 30. A pessoa jurídica que pretenda celebrar acordo de leniência deverá:

I - ser a primeira a manifestar interesse em cooperar para a apuração de ato lesivo específico, quando tal circunstância for relevante;

II - ter cessado completamente seu envolvimento no ato lesivo a partir da data da propositura do acordo;

III - admitir sua participação na infração administrativa

IV - cooperar plena e permanentemente com as investigações e o processo administrativo e comparecer, sob suas expensas e sempre que solicitada, aos atos processuais, até o seu encerramento; e

$\mathrm{V}$ - fornecer informações, documentos e elementos que comprovem a infração administrativa.

$\S 1$ o $\mathrm{O}$ acordo de leniência de que trata o caput será proposto pela pessoa jurídica, por seus representantes, na forma de seu estatuto ou contrato social, ou por meio de procurador com poderes específicos para tal ato, observado o disposto no art. $26 \mathrm{da}$ Lei $\mathrm{n}^{\circ} 12.846$, de 2013.

§ 2o A proposta do acordo de leniência poderá ser feita até a conclusão do relatório a ser elaborado no PAR.

A regulamentação flexibilizou a disposição de firmar-se acordo apenas com a primeira pessoa jurídica a manifestar interesse em cooperar, inserindo a expressão "quando tal circunstância for relevante", o que possibilitará outras pessoas jurídicas a firmarem acordos sobre o mesmo processo.

Também previu o Decreto o prazo máximo para a proposição do acordo de leniência, que deve se dar a até emissão do relatório final no Processo Administrativo de Responsabilização - PAR.

VI - no caso de os contratos mantidos ou pretendidos com o órgão ou entidade lesado, serão considerados, na data da prática do ato lesivo, os seguintes percentuais:

a) um por cento em contratos acima de $\mathrm{R} \$ 1.500 .000,00$ (um milhão e quinhentos mil reais);

b) dois por cento em contratos acima de $\mathrm{R} \$ 10.000 .000,00$ (dez milhões de reais);

c) três por cento em contratos acima de $\mathrm{R} \$ 50.000 .000,00$ (cinquenta milhões de reais);

d) quatro por cento em contratos acima de $\mathrm{R} \$ 250.000 .000,00$ (duzentos e cinquenta milhões de reais); e

e) cinco por cento em contratos acima de $\mathrm{R} \$ 1.000 .000 .000,00$ (um bilhão de reais).

Art. 18. Do resultado da soma dos fatores do art. 17 serão subtraídos os valores correspondentes aos seguintes percentuais do faturamento bruto da pessoa jurídica do último exercício anterior ao da instauração do PAR, excluídos os tributos:

I - um por cento no caso de não consumação da infração;

II - um e meio por cento no caso de comprovação de ressarcimento pela pessoa jurídica dos danos a que tenha dado causa;

III - um por cento a um e meio por cento para o grau de colaboração da pessoa jurídica com a investigação ou a apuração do ato lesivo, independentemente do acordo de leniência;

IV - dois por cento no caso de comunicação espontânea pela pessoa jurídica antes da instauração do PAR acerca da ocorrência do ato lesivo; e

$\mathrm{V}$ - um por cento a quatro por cento para comprovação de a pessoa jurídica possuir e aplicar um programa de integridade, conforme os parâmetros estabelecidos no Capítulo IV. 
Mesmo com a regulamentação, que demorou a vir, não foram superadas várias lacunas e problemas que a alteração legislativa seria capaz de resolver.

\subsection{A responsabilidade objetiva da pessoa jurídica na lei anticorrupção}

Outro aspecto importante e diferenciador da Lei Anticorrupção é a forma de responsabilização da pessoa jurídica.

Trata-se de tema de grande discussão doutrinária a necessidade ou não do elemento subjetivo (dolo ou culpa) na configuração do ilícito administrativo para efeitos de sanção.

Para Celso Antônio Bandeira de Mello ${ }^{13}$ e Daniel Ferreira ${ }^{14}$, é desnecessária a demonstração de culpa ou dolo para que a sanção seja aplicada, bastando a voluntariedade.

Já Heraldo Garcia Vitta (2003, p. 44) entende diversamente neste aspecto, expondo que "[...] o pressuposto da existência do ilícito administrativo, a nosso ver, além da voluntariedade, é o dolo ou a culpa."

Todavia, no âmbito da Lei Anticorrupção, há definição expressa de que a responsabilidade da pessoa jurídica se dá na forma objetiva ${ }^{15}$ para atos lesivos à Administração Pública, ou seja, independente de culpa ou dolo de seus prepostos.

Para a responsabilização objetiva da empresa bastará que exista nexo causal entre sua conduta e a lesão da Administração pública. Tal situação se conforma com o que prevê o Código Civil (art. 927), e amplia o rol de responsabilização objetiva no sistema jurídico brasileiro. As ações serão as praticadas pelos membros de direção da pessoa jurídica (Diretores, Conselheiros, etc.), e os demais funcionários que estiverem representando-a (SANTOS, BERTONCINI e CUSTÓDIO FILHO, 2014, p. 84).

Esta forma de responsabilidade facilita o exercício do poder sancionador pelo Estado, e exige dos agentes privados maior cuidado nas suas relações com o Poder Público.

Importante destacar que a previsão de responsabilidade objetiva não se confunde com a responsabilidade pelo risco integral, sob pena de violar-se o princípio da segurança

\footnotetext{
13 "Infração administrativa é o descumprimento voluntário de uma norma administrativa para a qual se prevê sanção cuja imposição é decidida por uma autoridade no exercício da função administrativa - ainda que não necessariamente aplicada nesta esfera." (BANDEIRA DE MELLO, 2014, p. 865).

14 "Nada obstante, em sintético juízo, ter-se-ia a infração administrativa, em termos analíticos, como um comportamento (voluntário) objetivamente típico (e de culpa a dolo exigível apenas em caráter excepcional e quando a lei o exigir), antijurídico e sancionável." (FERREIRA, 2009, p. 228).

${ }^{15}$ Lei $\mathrm{n}^{\circ} 12.846 / 13$ - Art. $2^{\circ}$ As pessoas jurídicas serão responsabilizadas objetivamente, nos âmbitos administrativo e civil, pelos atos lesivos previstos nesta Lei praticados em seu interesse ou benefício, exclusivo ou não.
} 
jurídica, pois caso a pessoa jurídica comprove que não foi violada a ordem jurídica, ou na situação de romper-se o nexo causal com a demonstração de que os atos não foram praticados por seus representantes, ou ainda que o funcionário que praticou o ato se deu em seu único benefício ou agiu fora de suas funções, incabível a responsabilização (MOREIRA NETO; FREITAS, 2014, p.13).

\section{Há segurança jurídica no acordo de leniência previsto na Lei Anticorrupção?}

Até o mês de janeiro de 2015, nenhum acordo de leniência previsto na Lei Anticorrupção tinha sido firmado, conforme notícia ${ }^{16}$ da Controladoria-Geral da União (CGU):

[...] 5. A CGU não celebrou, até o momento, nenhum acordo de leniência. Ao contrário, o que existe são processos de responsabilização (abertos em 3 de dezembro de 2014) contra oito empresas envolvidas na Lava Jato, que prosseguem em seu curso normal. Como as investigações estão em curso, a Controladoria pode vir a instaurar novos processos contra outras empresas, bem como abrir procedimentos administrativos para apurar responsabilidades de agentes públicos.[...]

Todavia, recentemente foi divulgada a celebração do que seria o primeiro acordo de leniência nos termos da Lei Anticorrupção. Conforme nota de esclarecimento ${ }^{17}$, em 15 de julho de 2016 foi firmado o acordo entre a empresa holandesa SBM Offshore e o Ministério da Transparência, Ministério Público Federal, Advocacia-Geral da União e a Petrobrás.

Tal acordo, porém, não foi homologado por discordância da $5^{\mathrm{a}}$ Câmara de Coordenação e Revisão do Ministério Público Federal, muito embora o Ministério da Transparência tenha expressado terem sido cumpridos todos os requisitos legais. Diante do parecer contrário, o processo retornou para readequação do acordo ou continuidade das investigações.

\footnotetext{
${ }^{16}$ Nota de esclarecimento: CGU esclarece notícias veiculadas na imprensa sobre o contato com o Ministério Público Federal (MPF) para tratar de acordo de leniência. Ministério da Transparência, Fiscalização e Controladoria-Geral da União, 22 jan. 2015. Disponível em: <http://www.cgu.gov.br/noticias/2015/01/notade-esclarecimento-acordo-de-leniencia> Acesso em: 24 nov. 2016.

17 Nota à imprensa - Acordo de Leniência com a SBM Offshore - Lei Anticorrupção. Ministério da Transparência, Fiscalização e Controladoria-Geral da União, 01 set. 2016. Disponível em: <http://www.cgu.gov.br/noticias/2016/09/nota-a-imprensa-acordo-de-leniencia-com-a-sbm-offshore> Acesso em: 24 nov. 2016.
} 
Sobre o caso, muito embora não existam elemento suficientes para mais ampla e profunda análise, sem tese, se atendidos todos os requisitos legais para o acordo, o infrator pode exigir, ainda que judicialmente, a sua homologação.

Sobre a hipótese, Maurício Zockun (2016, p. 02) entende que proposto o acordo de leniência dentro dos requisitos legais, o mesmo deverá ser aceito, pois não se trata de ato discricionário $^{18}$, mas de uma atividade vinculada, um direito subjetivo do signatário, especificando ainda que:

[...] cumpre observar que as hipóteses autorizadoras da formação do acordo de leniência exigem a ocorrência de alguns pressupostos: (i) que a pessoa jurídica proponente tenha supostamente praticado o ilícito descrito na Lei Anticorrupção (afinal, da frustração do acordo de leniência não decorre a presunção que a entidade proponente tenha cometido o ato ilícito curado pela lei); e, alternativamente, que a entidade proponente (ii) identifique os demais infratores, se for o caso, ou (iii) aporte documentos e informações que permitam a identificação do ilícito praticado, ou (iv) adote medidas de melhoria em seu programa de integridade (ou compliance, no jargão corporativo). [...] De toda sorte, atendidos estes requisitos, estarão reunidas as condições necessárias à celebração do acordo de leniência, viabilizando a concretização do interesse público preconizado pela Lei Anticorrupção pela identificação do ilícito e/ou seus agentes, interrupção da prática ilícita e efetiva concretização de programa de integridade. Assim, a Administração não goza de margem de liberdade para celebrar ou não o acordo de leniência uma vez constatada a ocorrência dos pressupostos necessários à sua formação. Isso porque a ordem jurídica elegeu este ato negocial como o meio mais adequado para tutela do interesse público [...]. (ZOCKUN, 2016, p. 01). Grifo nosso.

O que chama a atenção, é que diante do envolvimento em supostos atos de corrupção por inúmeras empresas no âmbito da Operação "lava jato" ${ }^{19}$, ao longo de mais de um ano de vigência da regulamentação da Lei Anticorrupção, apenas um acordo de leniência tenha sido firmado, e pendente de homologação. Ao passo que o número de colaborações premiadas com pessoas físicas já passou de cinquenta ${ }^{20}$, número próximo aos acordos de leniência firmado pelo CADE, como já referenciado.

Releva perguntar se a norma está atingindo sua finalidade.

19 "[...] A operação Lava Jato é a maior investigação de corrupção e lavagem de dinheiro que o Brasil já teve. Estima-se que o volume de recursos desviados dos cofres da Petrobras, maior estatal do país, esteja na casa de bilhões de reais. Soma-se a isso a expressão econômica e política dos suspeitos de participar do esquema de corrupção que envolve a companhia. (Ministério Público Federal) Disponível em <http://lava jato.mpf.mp.br/entenda-o-caso. > Acesso em 28 nov. 2016.

${ }^{20}$ O Globo on line. De 52 acordos de delação premiada firmados pela Lava-Jato nesses últimos dois anos, apenas 13 foram celebrados com réus presos. 30 mai. 2016. Disponível em <http://oglobo.globo.com/brasil/de-52acoes-de-delacao-premiada-apenas-13-foram-feitas-com-reus-presos-19394364\#ixzz4RQIhuFrm>. Acesso em 29 nov. 2016. 
Tiago Marrara, quando aborda as infrações licitatórias que podem ser objeto de leniência, faz sérias e embasadas críticas, explicitando que seria mais producente a extensão de benefícios desta natureza num único acordo; que há falta de utilidade pela aplicação no aspecto contratual da lei de licitações sem contemplar o aspecto criminal e a impossibilidade de incluir a pessoa física; e que a atenuação da pena de multa não tem parâmetros legais, concluindo que (2015, p. 524-525):

\begin{abstract}
Essas poucas reflexões bastam para evidenciar que a criação de uma leniência licitatória na Lei Anticorrupção (fora da própria Lei de Licitações) e com base em um dispositivo legal cuja redação se revela confusa, questionável e incompleta parece ter levado a mais problemas do que soluções. Isso a torna um instrumento de cooperação obscuro, perigoso e desinteressante. Que infrator desejará celebrar uma leniência cujo regime jurídico não tem qualquer sustentação firme na lei, cujos benefícios se mostram duvidosos e que não se estende a pessoas físicas? E mais: um acordo que não gera benefícios civis e nem vantagens em processos conduzidos com supedâneo na Lei Anticorrupção e na Lei de Defesa da Concorrência. Muitas são as dúvidas e as indagações que precisarão ser respondidas para que o mecanismo de consensualização constante do art. 17 efetivamente saia do papel.
\end{abstract}

Sobre a definição de redução do valor da multa quando proposto o acordo de leniência, nem a Lei anticorrupção ou mesmo sua regulamentação preveem expressamente:

Art. 23. Com a assinatura do acordo de leniência, a multa aplicável será reduzida conforme a fração nele pactuada, observado o limite previsto no $\S 2^{\circ}$ do art. 16 da Lei $\mathrm{n}^{\mathrm{O}} 12.846$, de 2013.

$\S 1^{\circ} \mathrm{O}$ valor da multa previsto no caput poderá ser inferior ao limite mínimo previsto no art. $6^{\circ}$ da Lei $n^{\circ} 12.846$, de 2013.

Este tema é tratado por Mauricio Zockun (2016, p. 02):

Registre, neste particular, que a inexistência de uma pauta objetiva capaz escalonar a mitigação dessas penalidades - senão que para dosar sua imposição -, causa inegável insegurança à entidade leniente, especialmente em razão das pesadas multas que lhe são imponíveis.

A solução nestes casos perpassa pela aplicação dos princípios da razoabilidade, da proporcionalidade e da adequação dos atos administrativos à finalidade pública perseguida por meio dessa lei, sem embargo do inegável conteúdo aberto destes específicos comandos jurídicos.

A discricionariedade e a arbitrariedade são situações bem diversas, assim como pontua a doutrinadora cubana Gretel Arias Gayoso (2010, p. 20-21):

La impossibilidad de actuar arbitrariamente conecta com la idea general de los límites a lo discrecional y exige una reflexión inaplazable. Discrecionalidad y arbitrariedad constituyen conceptos jurídicos totalmente diferentes y opuestos. La 
discrecionariedad no es sinónimo de arbitrariedade, sino el ejercicio de una potestad legal que posibilita a la Administración una estimación subjetiva para escojer la solución que mejor represente la finalidad de la norma, la utilidad o el interés general. La arbitrariedad, em cambio, se caracteriza por expresar la voluntad ilegítima de quien ejerce el poder; no constituye una potestad reconocida por el derecho sino una definición que se halla fuera del derecho y se extiende a los principios generales, em una suerte de consecuencia del bloque de legalidad.

Na consensualização em relação à sanção, o administrado tem o direito de obter a melhor solução, "o menor gravame possível". (FERREIRA, 2009, p. 68).

O ideal seria a previsão legal com os requisitos para a redução dos valores da multa, uma vez que se pode incorrer em arbitrariedades e favorecimentos, apenas ajustados em razão do caso concreto na aplicação dos princípios da razoabilidade e proporcionalidade propostos por Zockun.

Até a modificação legislativa para o preenchimento das lacunas no que diz respeito ao acordo de leniência, haverá maior risco com a dependência de definição do Poder Público, como num exercício de acerto e erro, em que a experiência poderá criar precedentes e orientações para ajustes futuros.

\section{CONSIDERAÇÕES FINAIS}

Embora o tema mereça maior aprofundamento, com o estudo de cada particularidade do acordo de leniência previsto na Lei Anticorrupção, verifica-se nesta singela pesquisa, que parece não existir segurança jurídica para a empresa que deseje propor acordo de leniência nos moldes que a legislação se encontra.

Muito embora seja um enorme avanço a definição de sanções relativas à corrupção com o alcance de pessoas jurídicas envolvidas, o que é extremamente necessário para a busca da moralidade e da ética também no setor privado, o mecanismo de alternatividade a estas sanções administrativas e civis por meio do acordo de leniência se mostra pouco atraente e transparente, o que pode inviabilizá-lo.

De acordo com o estudo realizado identifica-se que não há critérios claros e precisos na norma que indiquem objetivamente a vantajosidade com o acordo, no que se refere aos percentuais de redução das multas, por exemplo, o que pode trazer insegurança jurídica aos atores envolvidos.

Outrossim, trata-se de direito do administrado a aplicação de penalidade menos gravosa, e por isso o mesmo precisa ter plena e prévia ciência dos benefícios que podem advir 
se resolver colaborar firmando acordo de leniência com o Poder Público, sem que fique ao arbítrio deste, questões que deveriam ser pormenorizadas na lei. Até por que, em contrapartida, a empresa assume compromissos de grande monta (confissão, auxílio irrestrito nas investigações, etc.).

Ainda, há falta de repercussão do acordo em outras esferas e penalidades, inclusive em relação à improbidade administrativa, como se dava com a previsão da natimorta Medida Provisória no 703/2015, além da possibilidade de suspensão de punibilidade criminal, como ocorre no âmbito do CADE, por outro lado, obriga o participante a confessar o ilícito (abrindo mão do princípio da presunção de inocência).

Tais circunstâncias se configuram como riscos que podem dificultar, quiçá desestimular a empresa a firmar o acordo de leniência.

Com isso, sem que se considere a possibilidade de englobar-se num acordo outras hipóteses de penalização administrativa ou judicial, possivelmente não haverá maior interesse de pessoas jurídicas em firmá-lo, contrariando o que poderia ser um importante indutor de redução de impunidade por ato de corrupção, não atingindo os objetivos legais.

Não é por outro motivo que duas propostas se encontram em discussão na Câmara dos Deputados (Projetos de Lei no 3636/2015 e 5280/2016).

Aguarda-se que tais modificações no instrumento de leniência, se ocorrerem, tragam maior viabilidade na sua implementação à pessoa jurídica, atraindo soluções de conflito alternativos à sanção, com o atingimento do interesse público, assim como tem ocorrido no caso da delação premiada e do acordo de leniência no âmbito do CADE, o que motiva a continuidade do estudo.

\section{REFERÊNCIAS}

BANDEIRA DE MELLO, Celso Antônio. Curso de direito administrativo. 31. ed. São Paulo: Malheiros, 2014.

BERTONCINI, Mateus Eduardo Siqueira Nunes; MARTINS, Grasiele Borges. A adequada aplicação das sanções por ato de improbidade administrativa como forma de preservação de direitos fundamentais. Revista Jurídica, Curitiba, n. 25, Temática n. 9, p. 153-183, 2010-2.

FERREIRA, Daniel. Teoria geral da infração administrativa a partir da Constituição Federal de 1988. Belo Horizonte: Fórum, 2009. 
Alternativas legais à sanção administrativo-ambiental: uma eventual questão de dignidade da pessoa humana e de sustentabilidade da atividade empresarial. Revista Jurídica, Curitiba, n. 22, Temática n. 6, p. 55-75, 2009.

GALEANO, Eduardo. As veias abertas da América Latina. Estudo latino-americano, v. 12. Tradução de Galeano de Freitas. Rio de Janeiro, Paz e Terra: 1976.

GAYOSO, Grethel Arias. A vueltas con la discricionalidad administrativa. Revista de Derecho, Universidad Católica del Uruguay, n. 05, p. 11-26, 2010.

JUSTEN FILHO, Marçal. A "Nova" Lei Anticorrupção Brasileira (Lei Federal 12.846). Informativo Justen, Pereira, Oliveira e Talamini, Curitiba, $\mathrm{n}^{\circ}$ 82, dez. 2013. Disponível em $<$ http://www.justen.com.br//informativo.php?\&informativo $=82 \& \operatorname{artigo}=1110 \& \mathrm{l}=\mathrm{pt}>, \quad$ acesso em 28 nov 2016.

MOREIRA NETO, Diogo de Figueiredo; FREITAS, Rafael Véras de. A juridicidade da Lei Anticorrupção: reflexões e interpretações prospectivas. Fórum Administrativo - FA, Belo Horizonte, ano 14, n. 156, p. 9-20, fev. 2014.

MARRARA, Thiago. Acordos de leniência no processo administrativo brasileiro: modalidades, regime jurídico e problemas emergentes. Revista Digital de Direito Administrativo - RDDA, Ribeirão Preto, v.2, n. 2, p. 509-527, 2015.

PADILHA FILHO, Valmor Antônio. Corrupção e a atividade empresarial. 237 fls. Dissertação (Mestrado em Direito), Centro Universitário Curitiba, Curitiba, 2010.

SALLES, Marlon Roberth; BENNWART JÚNIOR, Clodomiro José. O Acordo de Leniência: uma análise de sua compatibilidade constitucional e legitimidade. Revista de Direito Público, Londrina, v.10, n. 3, p.31-50, set./dez. 2015.

SANTOS, Anacleto Abduch; BERTONCINI, Mateus; CUSTÓDIO FILHO, Ubirajara. Comentários à Lei no 12.846/2013. São Paulo: Revista dos Tribunais, 2014.

SOUZA, Jessé. Como é possível perceber o Brasil contemporâneo de modo novo? In: SOUZA, Jessé (Coord.). Ralé brasileira: quem é e como vive. Belo Horizonte: Ed. da UFMG, 2009. p. 103-122.

VITTA, Heraldo Garcia. A sanção no direito administrativo. São Paulo: Malheiros, 2003. (p. 25-68)

ZOCKUN, Maurício. Vinculação e Discricionariedade no Acordo de Leniência. Revista Colunistas Direito do Estado, 2016, n. 142. 14 abr. 2016. Disponível em $<$ http://www.direitodoestado.com.br/colunistas/Mauricio-Zockun/vinculacao-ediscricionariedade-no-acordo-de-leniencia>. Acesso em: 08 nov. 2016.

Nota de esclarecimento: CGU esclarece notícias veiculadas na imprensa sobre o contato com o Ministério Público Federal (MPF) para tratar de acordo de leniência. Ministério da Transparência, Fiscalização e Controladoria-Geral da União, 22 jan. 2015. Disponível em: 
<http://www.cgu.gov.br/noticias/2015/01/nota-de-esclarecimento-acordo-de-leniencia> Acesso em: 24 nov. 2016.

CONVENCIÓN INTERAMERICANA CONTRA LA CORRUPCIÓN - OAS. Disponível em $<$ http://www.oas.org/es/sla/ddi/tratados_multilaterales_interamericanos_B58_contra_Corrupcion.asp> Acesso em 24 nov. 2016.

\section{CONVENÇÃO DAS NAÇÕES UNIDAS CONTRA A CORRUPÇÃO. Disponível em <https://www.unodc.org/documents/lpo- brazil//Topics_corruption/Publicacoes/2007_UNCAC_Port.pdf> Acesso em 24 nov. 2016.}

Nota à imprensa - Acordo de Leniência com a SBM Offshore - Lei Anticorrupção. Ministério da Transparência, Fiscalização e Controladoria-Geral da União, 01 set. 2016. Disponível em: <http://www.cgu.gov.br/noticias/2016/09/nota-a-imprensa-acordo-de-leniencia-com-asbm-offshore> Acesso em: 24 nov. 2016.

O GLOBO ON LINE. De 52 acordos de delação premiada firmados pela Lava-Jato nesses últimos dois anos, apenas 13 foram celebrados com réus presos. 30 mai. 2016. Disponível em $<$ http://oglobo.globo.com/brasil/de-52-acoes-de-delacao-premiada-apenas-13-foram-feitascom-reus-presos-19394364\#ixzz4RQIhuFrm>. Acesso em 29 nov. 2016.

MINISTÉRIO PÚBLICO FEDERAL. Caso Lava jato - entenda o caso. Disponível em $<$ http://lava jato.mpf.mp.br/entenda-o-caso.> Acesso em 28 nov. 2016. 